\title{
DERECHOS HUMANOS, PROCESO JURISDICCIONAL Y SUS MODOS NORMALES DE TERMINACIÓN'
}

\section{Human rights, jurisdictional proceedings and normal ending of the court proceedings}

\author{
LUIS ANDRÉS CUCARELLA GALIANA² \\ Universitat de València \\ luis.a.cucarella@uv.es
}

Cómo citar/Citation

Cucarella Galiana, L. A. (2019).

Derechos humanos, proceso jurisdiccional y

sus modos normales de terminación.

Anuario Iberoamericano de Justicia Constitucional, 23(1), 143-173.

doi: https://doi.org/10.18042/cepc/aiic.23.05

\section{Resumen}

En el trabajo se realiza un análisis del Consejo de Europa y los órganos que lo integran, prestando especial atención al Tribunal Europeo de Derechos Humanos.

1 El presente trabajo ha sido realizado en el marco del proyecto de investigación con núm. de referencia DER2015-69722-R (MINECO/FEDER), Ministerio de Economía y Competitividad, Gobierno de España.

2 Catedrático de Derecho Procesal de la Facultad de Derecho de la Universidad de Valencia, España. doctor Derecho por la Universidad de Bolonia, Italia, y por la Universidad de Valencia, España. Profesor Honorario de la Universidad Continental de Perú. Miembro del Instituto Iberoamericano de Derecho Procesal, Asociación Española de Profesores de Derecho Procesal, Asociación Colombiana de Derecho Procesal Constitucional, vicepresidente para Europa de la Asociación Mundial de Justicia Constitucional, Asociación Paraguaya de Derecho Procesal Constitucional, Asociación Panameña de Derecho Procesal Constitucional, Asociación Argentina de Justicia Constitucional, Asociación Brasileña de Justicia Constitucional, Asociación Brasileña de Derecho Procesal Constitucional. 
En dicho análisis se concretan los principios del proceso seguido ante este órgano jurisdiccional y se analizan los modos normales de terminación del proceso. En este sentido, se clasifican y sistematizan los diferentes tipos de sentencias que puede dictar este órgano jurisdiccional.

\section{Palabras clave}

Consejo de Europa; Tribunal Europeo de Derechos Humanos; proceso jurisdiccional; sentencia; derechos humanos.

\section{Abstract}

This paper analyzes the Council of Europe and its internal bodies, with special attention given to the European Court of Human Rights. This analysis specifies the principles of the proceeding before this Court and the normal ending means. In this regard, this paper classifies the different types of resolutions handed down by that Court.

\section{Keywords}

Council of Europe; European Court of Human Rights; jurisdictional proceedings; judgment; Human rights. 


\section{SUMARIO}

I. EL TRIBUNAL EUROPEO DE DERECHOS HUMANOS COMO ÓRGANO JURISDICCIONAL DEL CONSEJO DE EUROPA: 1. Origen. 2. Finalidad. 3. Órganos: 3.1. Órgano ejecutivo. 3.2. Órgano deliberante. 3.3. Órgano jurisdiccional. II. PRINCIPIOS PROCESALES: 1. Relativos a las partes: 1.1. Dualidad de posiciones. 1.2. Contradicción o audiencia. 1.3. Igualdad. 2. Relativos al proceso: el principio dispositivo. 3. Del procedimiento: 3. 1. Forma de las actuaciones. 3.2. Idioma. 3.3. Publicidad. III. MODO NORMAL DE TERMINACIÓN DEL PROCESO: 1. Clases de sentencia: 1.1. Sentencias de fondo o procesales. 1.2. Sentencias condenatorias o absolutorias. 1.3. Sentencias definitivas o no definitivas. 1.4. Sentencias de tutela individual o colectiva. IV. CONCLUSIONES. BIBLIOGRAFía.

\section{EL TRIBUNAL EUROPEO DE DERECHOS HUMANOS COMO ÓRGANO JURISDICCIONAL DEL CONSEJO DE EUROPA}

\section{ORIGEN}

El fin de la Segunda Guerra Mundial dio paso a los intentos de reconstruir la vieja Europa. Como figura esencial en dicha reconstrucción, debemos señalar el papel que ha desempeñado el Consejo de Europa (CE), cuyo Estatuto está hecho en Londres el 5 de mayo de 1949 (ECE).

Los trabajos preparatorios para la creación de este organismo comenzaron en el Congreso de La Haya de 1948, y en él intervino una veintena de países. Son varias las resoluciones adoptadas, pero, en lo que nos interesa, se tomó la decisión de crear «una unión económica y política con el fin de garantizar la seguridad, la independencia económica y el progreso social, la convocatoria de una asamblea consultiva elegida por los parlamentos, la elaboración de una carta europea de derechos humanos y de un tribunal para aplicar sus decisiones».

Sin embargo, el enfrentamiento político e ideológico entre los países orientales y occidentales de Europa determinó que los primeros quedaran descolgados de este proceso.

El 5 de mayo de 1949, en Londres, tuvo lugar la firma del tratado constitutivo del CE. Son diez los países que lo firmaron: los Reinos de Bélgica, 
Dinamarca, Países Bajos, Noruega, Suecia, Gran Bretaña e Irlanda del Norte, repúblicas francesa e irlandesa, y el Gran Ducado de Luxemburgo. A día de hoy, son un total de 47 países europeos los que forman parte del $\mathrm{CE}^{3}$.

En este trabajo vamos a centrarnos en el papel que desempeña el CE, y sobre todo, el tribunal para la protección de los derechos humanos que se ha creado en el marco de dicho Consejo. Nos referimos al Tribunal Europeo de Derechos Humanos (TEDH).

Son muchos los aspectos que podrían tratarse en profundidad en relación con dicho órgano jurisdiccional. En este sentido, por ejemplo, los principios sobre la base de los cuales se estructura el proceso seguido ante el mismo, cuestión a la que nos referiremos un poco más adelante. O también podría ser interesante el análisis de los aspectos relativos a los medios de impugnación que proceden contra las sentencias y decisiones del TEDH (Cucarella, 2016: 307-325). Sin embargo, el objetivo que nos marcamos en este trabajo es centrarnos, sobre todo, en los aspectos relativos a los modos de terminación de los procesos seguidos ante el TEDH. Creemos interesante analizar los modos normales de terminación del proceso. Es decir, nos referimos a los casos en que el Tribunal entra a conocer de la pretensión interpuesta, dictando la correspondiente sentencia, en la que se pronuncia sobre la adecuación de dicha pretensión con el Convenio para la protección de los derechos y de las libertades fundamentales, hecho en Roma el 4 de noviembre de 1950 (CEDH), y los protocolos adicionales (Canosa, 2009: 79-93; Carrillo, 1998: 63-72; González, 2000: 13-36).

En ese momento, deberemos prestar atención a los requisitos de la sentencia que se dicte. En relación con la misma, consideramos de extraordinario interés prestar atención a las sentencias para la tutela colectiva de los derechos, entre ellas, la denominada sentencia piloto (Morte, 2013: 920-9214'; Abrisketa, 2013: 73-99).

3 A los diez a los que nos hemos referido hay que sumar los que siguen: Albania, Armenia, Andorra, Austria, Azerbaiyán, Bosnia y Herzegovina, Bulgaria, Croacia, Chipre, República Checa, Estonia, Finlandia, Georgia, Grecia, Hungría, Islandia, Irlanda, Letonia, Liechtenstein, Lituania, Luxemburgo, Malta, República de Moldavia, Mónaco, Montenegro, Polonia, Rumanía, Federación Rusa, San Marino, Serbia, República Eslovaca, Eslovenia, España, Suiza, Macedonia, Turquía y Ucrania. Tienen la condición de Estados observadores la Santa Sede, Canadá, México, Estados Unidos de Norteamérica, Israel y Japón.

$4 \mathrm{Al}$ respecto, afirma que «el procedimiento de Sentencia piloto tiene por objeto tratar de grandes grupos de demandas basadas en el mismo problema estructural o sistémico o cualquier otro tipo de defecto similar que haga que se presenten un gran número 
Mediante este tipo de sentencia, ya avanzamos al lector que el TEDH pretende otorgar una tutela colectiva de derechos humanos en los supuestos de violaciones masivas de derechos ${ }^{5}$. No obstante, también prestaremos especial atención a las sentencias que, sin ser piloto, incluyen una serie de medidas generales que debe adoptar el Estado condenado. En ese punto, prestaremos especial atención al análisis de la postura del TEDH en los casos en que, con ocasión de una demanda individual, detecta que la violación denunciada la produce una norma de rango constitucional.

En todo caso, antes de analizar los aspectos que hemos señalado, vamos a completar la introducción que estamos realizando, profundizando en el estudio de la finalidad que se persigue en el CE, así como ofreciendo una visión general de los órganos que lo integran. Posteriormente analizaremos las notas características del proceso seguido ante este órgano jurisdiccional y los modos de terminación.

\section{FINALIDAD}

La finalidad del CE aparece claramente expresada en el art. 1 ECE. Así, en la letra «a» del mismo se subraya que la misma "consiste en realizar una unión más estrecha entre sus miembros para salvaguardar y promover los ideales y los principios que constituyen su patrimonio común y favorecer su progreso económico y social ${ }^{6} »$. Como se indica a continuación en la letra «b», esta finalidad se pretende alcanzar «a través de los órganos del Consejo, mediante el examen de los asuntos de interés común, la conclusión de acuerdos y la adopción de una acción conjunta en los campos económicos, social, cultural, científico, jurídico y administrativo, así como la salvaguardia y la mayor efectividad de los derechos humanos y las libertades fundamentales» (Casadevall, 2012: 25-26).

Para alcanzar los objetivos de la protección real y efectiva de los derechos humanos, el art. 3 ECE añade que "cada uno de los Miembros del Consejo de Europa reconoce el principio del imperio del Derecho y el principio en virtud del cual cualquier persona que se halle bajo su Jurisdicción ha de gozar

de casos repetitivos (lo cual representa una parte importante de la carga de trabajo del TEDH)».

5 Dejamos fuera de nuestro trabajo el análisis de otros fenómenos tendentes a crear una jurisdicción penal supranacional, cuya idea adquiere fuerza tras el desarrollo de los juicios de Núremberg y Tokio. Sobre los mismos, Gimeno, 1998: 1766-1768.

6 En este contexto creemos que deben tenerse presentes las palabras que preceden al articulado del ECE, pues claramente se subraya la finalidad que se persigue. 
de los derechos humanos y de las libertades fundamentales, y se compromete a colaborar sincera y activamente en la consecución de la finalidad definida en el capítulo primero».

La sede del CE es Estrasburgo (art. 11 ECE), y sus idiomas oficiales son el francés y el inglés (art. 12 ECE).

\section{3. ÓRGANOS}

Los órganos del CE pueden clasificarse en órganos de naturaleza ejecutiva, deliberante y jurisdiccional. En concreto, se trata del Comité de Ministros, la Asamblea Consultiva o Parlamentaria —estando ambos órganos, asistidos por la Secretaría del Consejo- (art. 10 ECE) y el TEDH.

\section{1. Órgano ejecutivo}

Los aspectos relativos al Comité de Ministros se regulan en el capítulo IV ECE (arts. 13-21). El Comité es el órgano que actúa en nombre del CE (art. 13 ECE). Cada miembro tiene un representante en el Comité de Ministros y cada representante tiene un voto. Dicho representante es el ministro de Asuntos Exteriores de cada uno de esos Estados (art. 14 ECE) ${ }^{7}$. La competencia del Comité es examinar, motu proprio o por recomendación de la Asamblea Consultiva, las medidas que sean necesarias para lograr la finalidad del CE, incluida la conclusión de convenios y acuerdos y la adopción por los Gobiernos de los diferentes Estados parte de una política común respecto a determinados asuntos (art. 15a ECE). Las conclusiones a las que llegue el Comité podrán revestir la forma de recomendaciones a los Gobiernos ${ }^{8}$ (art. 15b ECE).

El Comité es el órgano del CE que supervisa el cumplimiento de las sentencias dictadas por el TEDH (Pastor, 2000: 195)'.

Como regla, las reuniones del Consejo se celebran a puerta cerrada y en la sede del Consejo (art. 21 ECE) (Casadevall, 2012: 26-27).

7 Este art. añade que «cuando un Ministro de Asuntos Exteriores no pueda asistir a las sesiones, o cuando otras circunstancias lo aconsejen, podrá designarse un suplente que actúe en su lugar; éste será, en la medida de lo posible, un miembro del Gobierno de su país».

8 De acuerdo con lo previsto en el art. 20a II, estas recomendaciones, para ser aprobadas, requieren de la unanimidad de todos los miembros.

9 Al respecto, afirma que «en casos graves el Comité de Ministros podrá utilizar la presión moral o política contra el Estado infractor, e incluso podrá dejar en suspenso el derecho de representación el miembro del Consejo de Europa e invitarle a retirarse, o llegar a expulsarle $[\ldots] »$. 


\section{2. Órgano deliberante}

La regulación de la Asamblea Consultiva se incluye en el capítulo V (arts. 22-33 ECE). La Asamblea es el órgano deliberante del CE. Delibera sobre los asuntos que son de su competencia y transmite sus conclusiones al Comité de Ministros (art. 22 ECE). Así, en concreto, la Asamblea puede formular recomendaciones sobre cualquier cuestión que responda a la finalidad del CE (art. 23a ECE). Esta Asamblea se conoce también comúnmente como asamblea parlamentaria. Entre las funciones que tiene encomendadas, destacamos las relativas a la elección del secretario general del CE, la de los jueces del TEDH, y la elección de los miembros del Comité Europeo para la prevención de la tortura.

La Asamblea está constituida por representantes de cada uno de los Estados miembros, elegidos por su Parlamento. Cada Estado tiene un número de representantes en la Asamblea ${ }^{10}$. Siendo un total de $318^{11}$.

Las sesiones de la Asamblea se desarrollan en la sede del Consejo (art. 33 ECE), y sus deliberaciones serán públicas, a menos que se acuerde lo contrario (art. 35 ECE) (Casadevall, 2012, 27-28).

Como hemos señalado anteriormente, la Secretaría asiste al Comité de Ministros y a la Asamblea Consultiva (art. 10 ECE). La regulación de la misma se contiene en el capítulo VI (arts. 36-37 ECE). Dicha Secretaría está compuesta por un secretario general, un secretario general adjunto y el personal necesario (art. 36a ECE) (ibid.: 28).

\section{3. Órgano jurisdiccional}

El CEDH, tras la enumeración de los derechos que resultan protegidos, incluye en el capítulo II (arts. 19-51) la regulación relativa al mecanismo de control que se prevé. En concreto, se regulan los aspectos referentes al TEDH. En este sentido, el art. $19 \mathrm{CEDH}$ dispone que, «con el fin de asegurar el respeto a los compromisos que resultan para las Altas Partes Contratantes del presente Convenio y sus Protocolos, se instituye un Tribunal Europeo de

10 Como indica el art. 25a, párr. 2, «cada uno de los representantes tendrá la nacionalidad del Miembro que represente y no podrá ser a la vez miembro del Comité de Ministros».

11 A título de ejemplo, los países que tienen un mayor número de representantes, un total de dieciocho, son, entre otros, Italia, Reino Unido, Alemania o Francia. Con doce, por ejemplo, España o Turquía. Austria tiene un total de seis representantes. Andorra, o San Marino, tienen un total de dos.

Puede verse el art. 26 ECE, en el que se fija la distribución de representantes que corresponden a cada Estado. 
Derechos Humanos, en lo sucesivo denominado "el Tribunal". Funcionará de manera permanente».

Como puede apreciarse el CEDH ha llevado a la instauración de un órgano jurisdiccional al que le compete el conocimiento de las demandas por violación de los derechos fundamentales protegidos en el ámbito del $\mathrm{CEDH}$ y sus protocolos adicionales (Bondia, 2008: 219-252; Ripoll, 2008: 99-116; Cancio, 2017: 271-290).

\section{PRINCIPIOS PROCESALES}

\section{RELATIVOS A LAS PARTES}

El TEDH tiene básicamente competencia para conocer dos tipos de procesos en virtud de lo regulado en los arts. 33 y $34 \mathrm{CEDH}$. Por su importancia, y como pretendemos analizar la protección de los derechos fundamentales en el ámbito europeo, vamos a centrarnos en el análisis de las cuestiones procesales relativas al proceso iniciado en virtud de lo previsto en el art. $34 \mathrm{CEDH}$.

\subsection{Dualidad de posiciones}

Como hemos señalado más arriba, el TEDH desempeña una labor jurisdiccional a través de un proceso. La naturaleza heterocompositiva del mismo implica que el Tribunal aplique las disposiciones del CEDH y de sus protocolos al caso concreto sobre la base de una dualidad de posiciones. Nótese, por otro lado, que estamos hablando de dualidad de posiciones y no de dualidad de partes.

\subsection{Contradicción o audiencia}

Las partes deben intervenir en el proceso con todas las garantías (Fernández Sánchez, 2000: 165-168). Así, por ejemplo, es preciso dar al demandado la posibilidad de conocer las alegaciones y peticiones formuladas por el demandante. Debe ser efectiva la posibilidad de conocer y poder contradecir todos los materiales de hecho y de derecho que puedan influir en la decisión judicial. El CEDH y el Reglamento del Tribunal Europeo de Derechos Humanos, de 14 de noviembre de 2016 (RTEDH), así lo contemplan.

\subsection{Igualdad}

Las partes deben poder actuar teniendo las mismas posibilidades procesales de actuación. Al respecto, no sería razonable prever prerrogativas o 
privilegios en beneficio del Estado demandado y en perjuicio del particular demandante.

El hecho de que en el proceso intervenga un Estado no debe implicar que este tenga una serie de prerrogativas o privilegios frente al particular demandante.

No obstante, consideramos que hay dos cuestiones relativas al desarrollo del proceso ante el TEDH que no se ajustan a las exigencias de igualdad y a las garantías procesales necesarias. A ellas vamos a referirnos brevemente a continuación.

En primer lugar, es criticable que la sala que conoce de una demanda individual dirigida contra un Estado parte esté integrada, entre otros, por el magistrado designado por el Estado demandado ${ }^{12}$ (art. 26.1 RTEDH). Es cierto que dicho artículo regula la posibilidad de abstención de dicho magistrado. Sin embargo, no le obliga a ello, de igual modo que tampoco permite su recusación por tener un conflicto de intereses. No perdamos de vista que dicho magistrado está integrando la sala que está juzgando una eventual violación de derechos humanos cometida por el Estado del que es nacional.

Desde nuestro punto de vista, el hecho de que sea el magistrado del Estado sobre cuya actuación se está discutiendo debería inhabilitar a ese magistrado por un problema de falta de imparcialidad objetiva.

Y por otro lado, también es claramente criticable que una vez que se dicte sentencia por la sala correspondiente, si finalmente la Gran Sala acabara conociendo de la impugnación de dicha sentencia, forman parte de la misma magistrados que han integrado la sala que ha dictado la sentencia que ahora se impugna. En concreto, el presidente de la sección a la que se repartió el asunto (art. 24.2a RTEDH) y el magistrado del Estado que ha sido demandado (art. 24.2b RTEDH). En este caso, la contaminación procesal es más que evidente (Pastor, 2000: 182 ${ }^{13}$; Fernández Sola, 2000, 182-183).

En definitiva, si bien estas dos cuestiones las tratamos con ocasión del estudio del principio de igualdad, puesto que creemos que implica una prerrogativa del Estado demandado que coloca en situación de inferioridad al

$12 \mathrm{Al}$ respecto, debe tenerse presente que el TEDH está integrado por 47 magistrados, uno por cada uno de los Estados que forman parte del CE. Como hemos señalado más arriba, la Asamblea Consultiva o Parlamentaria es la que designa a dichos magistrados.

13 En este sentido, afirma que «esta participación de pleno derecho en el reexamen o apelación ante la Gran Sala, tanto del juez vinculado al Estado parte en el litigio cuanto del presidente de la Sala que ha conocido del asunto en primera instancia, va en contra de la jurisprudencia del TEDH en materia de imparcialidad». 
particular demandante, también es una clara vulneración de las garantías procedimentales.

\section{RELATIVOS AL PROCESO: EL PRINCIPIO DISPOSITIVO}

El proceso seguido ante el TEDH es un proceso en el que está en juego un interés público: garantizar el debido respeto a los derechos y libertades fundamentales en el seno de la CE. Sin embargo, a pesar de ese interés implicado, el CEDH estructura el proceso seguido ante el TEDH sobre la base del principio dispositivo, si bien no de manera plena. En este sentido, el art. 39.1 CEDH permite que "en cualquier fase del procedimiento, el Tribunal podrá ponerse a disposición de las partes interesadas para conseguir una transacción sobre el asunto inspirándose para ello en el respeto a los derechos humanos tal como los reconocen el Convenio y sus Protocolos» (Sánchez, 1995: 242-246).

También es posible que el procedimiento pueda terminar por desistimiento, tal y como se desprende de lo previsto en el artículo 37.1a $\mathrm{CEDH}$ (Gimeno Sendra et al., 2007: 839).

\section{DEL PROCEDIMIENTO}

\subsection{Forma de las actuaciones}

La fase de enjuiciamiento propiamente dicha, está estructurada sobre la base del principio de oralidad. No ocurre lo mismo con la fase previa, que es escrita (ibid.: $839^{14}$ ).

\subsection{Idioma}

El art. 12 ECE dispone que los idiomas oficiales del Consejo sean el francés y el inglés. Pues bien, estas lenguas son las que también son oficiales en el proceso seguido ante el TEDH (art. 34.1 RTEDH). No obstante, en la fase inicial del procedimiento, hasta que se dicte la resolución sobre la admisibili-

$14 \mathrm{Al}$ respecto, afirma: «Con sus lógicas excepciones, es posible afirmar que el principio de escritura rige en la fase de instrucción, que comprende la de iniciación y de admisibilidad, en la que las partes se relacionan con el Tribunal a través de escritos (demanda del actor, observaciones y memoria de las partes, informes del Juez Ponente, resoluciones del Tribunal). Superada dicha barrera, la fase de enjuiciamiento está inspirada por el principio de oralidad» (capítulo VI del RTEDH rubricado «De la Vista»). 
dad de la demanda, la comunicación con el demandante y las observaciones que haga pueden realizarse en inglés o francés o en cualquiera de las lenguas oficiales de un Estado parte (art. 34.2 RTEDH) (ibid.: 876). Admitida la demanda, las actuaciones del actor deben realizarse en cualquiera de los dos idiomas oficiales, salvo que el presidente de la sala autorice a "continuar utilizando la lengua oficial de una Parte Contratante» (op. cit.).

$\mathrm{Si}$ nos referimos a las actuaciones de los Estados parte que hayan sido demandados, estas deben llevarse a cabo en alguna de las dos lenguas oficiales.

\subsection{Publicidad}

En la fase inicial del procedimiento, como norma general, rige el principio de publicidad. Así se desprende del art. 40.2 CEDH, en el que se dispone que «los documentos depositados en la Secretaría serán accesibles al público, a menos que el Presidente del Tribunal decida de otro modo ${ }^{15}$ ". En lo que se refiere a la fase de enjuiciamiento propiamente dicha, el art. 40.1 CEDH dispone que «la vista es pública, a menos que el Tribunal decida otra cosa por circunstancias excepcionales» (ibid.: 875) ${ }^{16}$.

Más adelante, con ocasión del estudio de la sentencia piloto, veremos que existen especiales normas de publicidad en lo relativo al inicio del procedimiento que culmine con la emisión de este tipo de sentencias, así como en relación con la sentencia piloto que acabe dictándose. Nos remitimos en este punto al estudio del art. 61 RTEDH que realizamos más adelante.

\section{MODO NORMAL DE TERMINACIÓN DEL PROCESO}

La manera normal de terminación del proceso seguido ante el TEDH tiene lugar cuando el Tribunal se pronuncia sobre la adecuación de la pretensión interpuesta al CEDH y a sus protocolos adicionales ${ }^{17}$. Es decir, cuando

15 Estos aspectos son desarrollados en el art. 33 RETDH.

16 En este sentido, sostiene que, «excepcionalmente, el acceso a la sala de audiencia podrá prohibirse para la prensa y el público en los mismos casos previstos en el art. 6.1 $\mathrm{CEDH}$ (protección de los valores o intereses de la sociedad, de los menores o de la vida privada de las personas)».

$17 \mathrm{Al}$ respecto, hay que tener presente que esa es la tutela que puede solicitarse y la que condiciona que pueda desarrollarse el proceso ante este Tribunal. De hecho, el art. 35.3a CEDH contempla como causa de inadmisión de una demanda que sea «incompatible con las disposiciones del Convenio o de sus Protocolos». 
el TEDH se pronuncia sobre el fondo del asunto. Para ello, la resolución que debe dictar es una sentencia.

En este apartado pretendemos estudiar las clases de sentencias que pueden dictarse, poniendo de relieve que, en ocasiones, la sentencia puede ser procesal. No obstante, vamos a prestar especial atención a las sentencias de fondo.

\section{CLASES DE SENTENCIA}

\subsection{Sentencias de fondo o procesales}

En primer lugar, hemos dicho que cuando el TEDH se pronuncia sobre el fondo del asunto debe dictarse una sentencia. El pronunciamiento sobre el fondo del asunto en sentencia lo encontramos en los arts. 28.1b CEDH para el caso de los Comités de tres magistrados; 29.1 CEDH, para el caso de las sentencias dictadas por las salas, y $31 \mathrm{CEDH}$, para las sentencias dictadas por la Gran Sala.

Sin embargo, no sería correcto decir que todas las sentencias que dicta el Tribunal son de fondo. Nos podemos encontrar con sentencias de carácter meramente procesal. Al respecto, debemos tener presente que el pronunciamiento relativo al archivo de una demanda admitida en los casos del art. 37 CEDH debe revestir la forma de sentencia (art. 43.3 RTEDH). Nos referimos a los casos en que el demandante no esté dispuesto a mantener la sentencia (art. 37.1a CEDH); que el litigio haya sido ya resuelto (art. 37.1 CEDH), o que por cualquier otro motivo verificado por el TEDH ya no esté justificada la prosecución del examen de la demanda (art. 37.1c CEDH).

Por su parte, el caso de archivo de la demanda por declaración unilateral del Estado demandado reviste la forma de decisión y no de sentencia (art. 43.3 RTEDH).

\subsection{Sentencias condenatorias o absolutorias}

Un segundo criterio de clasificación que podemos seguir es el que atiende al tipo de pretensión que haya interpuesto, y en función de la misma, la sentencia será de una clase u otra. Sin embargo, este criterio de clasificación solamente nos permite hablar de la existencia de sentencias de carácter condenatorio o absolutorio. En este sentido, debe tenerse presente el contenido del art. $34 \mathrm{CEDH}$, que regula el ejercicio de las acciones individuales.

Nosotros no compartimos las posiciones doctrinales que sostienen que las sentencias del TEDH no sean de carácter condenatorio (Gimeno Sendra et al., 2007: 842). Se apoyan en su argumentación diciendo que el Tribunal 
carece de poder coercitivo. Sin embargo, nosotros creemos que se están confundiendo dos cosas distintas. Por un lado, el Tribunal puede condenar si considera que se ha producido la violación del CEDH o de los protocolos. Es decir, el TEDH «declara», en la sentencia dictada al final del proceso, que se ha producido la violación de un derecho del CEDH o de sus protocolos, pero "condena» al Estado demandado a restituir al demandante en el goce pacífico de su derecho. No obstante, dicho Tribunal no puede ejecutar lo que ha juzgado. Ahora bien, la ausencia de poder coercitivo no desnaturaliza el carácter condenatorio del pronunciamiento. Existe un deber de prestación que se impone al Estado, cuyo incumplimiento puede llevar aparejada una serie de consecuencias.

Dicha sentencia se impone como cosa juzgada al Estado que ha sido condenado (Casadevall, 2012: 110). Como indica la doctrina, debe entenderse Estado en sentido amplio, es decir, la condena «se impone a todas las autoridades nacionales con independencia de la separación de poderes» (ibid.: 135).

\subsection{Sentencias definitivas o no definitivas}

Como tercer criterio a tener en cuenta, hay que atender al régimen de impugnación de la sentencia. Si la misma no fuera impugnable, se denomina sentencia definitiva. Al respecto, son definitivas (o firmes) las sentencias que dictan los comités de tres magistrados aplicando jurisprudencia bien establecida del Tribunal (arts. 28.1 y 28.2 CEDH). Contra dichas sentencias no procede medio de impugnación alguno.

También son definitivas las sentencias dictadas por las salas integradas por siete magistrados en los siguientes casos (art. 42, en relación con el art. 44.2 CEDH) (Sánchez, 1995: 206-2011):

1) Cuando las partes hayan declarado que no solicitarán la remisión del asunto ante la Gran Sala (art. 44.2a CEDH).

2) Cuando no haya sido solicitada la remisión del asunto ante la Gran Sala tres meses después de la emisión de la sentencia (art. 44.2b en relación con los arts. 31c y $43 \mathrm{CEDH}$ ).

3) Cuando el colegio de cinco magistrados de la Gran Sala rechace la remisión del asunto (art. 44.2c CEDH). Al respecto, hay que subrayar que, remitido el asunto a la Gran Sala, en el plazo de tres meses desde que se dictó la sentencia, un colegio de cinco jueces de la Gran Sala debe pronunciarse sobre la aceptación de la demanda a trámite. Para ello, se tiene en cuenta que el asunto platee una «cuestión grave relativa a la interpretación o aplicación del Convenio o de sus Protocolos, o una cuestión grave de carácter general» (art. 43.2 CEDH). 
La doctrina ha calificado a este colegio de cinco jueces como «un órgano de filtraje» (García, 1998: 213; Casadevall, 2012: 83; en general, Sánchez, 1995: 258-259) que debe valorar "la excepcionalidad de los casos y decidir si el asunto, ya juzgado antes por una Sala, plantea una cuestión importante sobre la interpretación o aplicación del Convenio o de sus Protocolos, o incluso una cuestión seria de carácter general que justifique el reenvío, un segundo examen y el pronunciamiento de una nueva sentencia» (Casadevall, 2012: 83).

Desde nuestro punto de vista, en este caso de impugnación, prima la dimensión objetiva del amparo sobre la subjetiva. Es decir, lo relevante ya no es tanto la tutela del derecho eventualmente lesionado, sino la formación de jurisprudencia sobre un asunto de trascendencia para la interpretación o aplicación del CEDH o sus protocolos adicionales.

En este sentido, y siguiendo las aportaciones doctrinales, pueden llegar a la Gran Sala cuestiones graves relativas a la interpretación del Convenio, que se entienden como los casos en que «el Tribunal no se ha pronunciado anteriormente o cuando la decisión a adoptar pueda tener incidencia en otros asuntos futuros y en la evolución de la jurisprudencia del Tribunal» (Casadevall, 2001: 144; también, Ruiloba: 2006).

Y se considera una cuestión grave relativa a la aplicación del CEDH la que implique "a un Estado tener que realizar modificaciones sustanciales en su Derecho nacional o las prácticas de su administración» (Casadevall, 2001: 144).

Por último, también es definitiva la sentencia que dicte la Gran Sala a partir de su pronunciamiento (art. 44.1 CEDH) (ibid.: 110).

\subsection{Sentencias de tutela individual o colectiva}

a) Sentencia para la tutela individual

Entendemos como sentencia para la tutela individual aquella en la que se concede la tutela exclusivamente a la persona que ha ocupado la posición activa en el proceso. Este sujeto es el único que puede beneficiarse de las medidas incluidas en el fallo para dar cumplimiento a la condena. Por ejemplo, debe tenerse presente que en la práctica son muy habituales las sentencias en las que se otorga el amparo, y el TEDH fija en el fallo el importe de la indemnización que debe abonar el Estado condenado. O, por otro lado, aunque el TEDH sigue el criterio de que el Estado es libre de elegir el medio que considere adecuado para dar cumplimiento a la sentencia (Fernández Sánchez, 2000: 173), en ocasiones, atendida la naturaleza del derecho lesionado, el Tribunal concreta le medida individual que debe adoptar el Estado condenado (Morte, 
2010: 229). En todo caso, cuando se impone cualquier otro tipo de pronunciamiento condenatorio, la única persona beneficiada es la que ha ocupado la posición activa en el proceso (Morte, 2013: 918) ${ }^{18}$.

\section{b) Sentencia para la tutela colectiva}

\section{b1) Sentencias con medidas generales o cuasipiloto. El caso especial de las violacio-} nes de derechos humanos provocadas por norma constitucional

Entendemos como sentencias de tutela colectiva aquellas en las que lo resuelto en el fallo, además de beneficiar al demandante, indirectamente, beneficia a otros sujetos que no han actuado como actores en dicho proceso. Nos estamos refriendo a sentencias con las que se puede lograr una protección colectiva de derechos humanos. Este tipo de sentencias son más novedosas y se van abriendo paso en la jurisprudencia del TEDH.

El primer supuesto es el de emisión de sentencias en las que el TEDH, además de señalar las medidas individuales de reparación que deben adoptarse por el Estado condenado, impone una serie de medidas de carácter general. Este tipo de sentencias se va abriendo paso poco a poco en la jurisprudencia del TEDH. Nosotros las consideramos como sentencias que sirven para la tutela colectiva de derechos, en la medida en que, indirectamente, se tutela a víctimas potenciales. Es decir, si el Estado condenado acaba adoptando las medidas de carácter general que se le imponen, se evita que en un futuro pueda haber nuevos sujetos cuyos derechos sean objeto de violación. Esta situación ha llevado a algunos autores a considerar este tipo de sentencias como cuasipiloto (Abrisketa, 2013: 75-76).

Sin embargo, hay aspectos en los que el TEDH no ha ido más allá a la hora de establecer las medidas generales que permitan evitar nuevas violaciones y que, por lo tanto, permitan la tutela colectiva de derechos. Este problema lo detectamos, sobre todo, en los casos en que una sentencia del TEDH detecta que la violación de un derecho humano la produce una norma constitucional.

Si prestamos atención a la jurisprudencia del Tribunal, podremos detectar cómo se ha manifestado muy cauto en estos casos.

Puede citarse como ejemplo la STEDH de 27 de agosto de 1991, caso Demicoli contra Malta ${ }^{19}$. Dicha violación la produjo la aplicación de una

18 En este sentido, afirma que «en algunas ocasiones, el TEDH indica a los Estados, en sus Sentencias, qué tipos de medidas deben adoptar, por ejemplo, medidas individuales de ejecución tales como la puesta en libertad de los demandantes [...]».

19

BDAW TEDH 1991\3. 
norma constitucional. Aunque el Estado maltés no fue condenado a modificar su Constitución, tras la sentencia, procedió a su reforma.

En concreto, Demicoli era el redactor jefe una revista política satírica de Malta. En su día, publicó un artículo satírico contra unos diputados. El art. 34 de la Constitución de Malta permitía que el Parlamento pudiera juzgar e imponer penas de reclusión y multas a quien ultrajara al Parlamento.

Demicoli fue juzgado ante el Parlamento y se le impuso una pena de multa. El TEDH entendió que se había vulnerado el art. 6.1 CEDH, al no haber sido juzgado y condenado por un tribunal independiente e imparcial. En este sentido, afirma:

En este caso, la Cámara de Representantes ejerció sin duda una función jurisdiccional resolviendo sobre la culpabilidad del demandante. La clave consiste en saber si se cumplió con la exigencia de imparcialidad. A efectos del artículo 6.1, ésta se aprecia subjetivamente, basándose en la convicción o el interés personales de un juez concreto en una situación concreta, y objetivamente determinando si ofrece las garantías suficientes para excluir a este respecto toda duda legítima. En la propia materia las apariencias pueden ser importantes, sobre todo en lo penal (ver, entre otras, la Sentencia Hauschildt de 24 mayo 1989 [TEDH 1989, 8], serie A núm. 154, pg. 21, ap. 46-48).

Los dos diputados cuyo comportamiento en el Parlamento criticaba el artículo enjuiciado, y que denunciaron a la Cámara un atentado contra los privilegios (apartado 11 supra), participaron en el procedimiento dirigido contra el acusado, incluida la constatación de culpabilidad y — salvo uno de ellos, que falleció en el intervalola fijación de la pena.

Por este motivo, la imparcialidad del órgano de decisión está sujeta a caución y se justifican en la materia los temores del señor Demicoli (Sentencia Hauschildt, previamente citada, serie A núm. 154, pg. 23, ap. 52).

Entre otros aspectos, el demandante solicitó que el TEDH se pronunciarse sobre la necesidad de reformar la Constitución maltesa en relación con los privilegios o prerrogativas del Parlamento. El TEDH, en la línea que hemos señalado más arriba, sostuvo que el CEDH no le permitía realizar dicha conden $\mathrm{a}^{20}$.

20 En el párr. 45 se afirma: «El demandante solicita al Tribunal que obtenga, con ayuda del Gobierno, el voto en el Parlamento de una resolución revocando las que le declararon culpable y condenaron a una multa, la derogación del artículo $11.1 \mathrm{k}$ por vía de 
No obstante, la sentencia, de manera indirecta, acabó provocando una reforma constitucional (Casadevall, 2012: 115). Es decir, se consiguió una tutela colectiva al haber procedido motu proprio a la reforma constitucional.

También resulta muy interesante prestar atención a diferentes sentencias dictadas contra Bosnia y Herzegovina.

La primera de ellas es la STEDH (Gran Sala) de 22 de diciembre de 2009, caso Sejdic et Finci contra Herzegovina ${ }^{21}$, y es un ejemplo en el que el Tribunal declara que un precepto de la constitución de una nación no cumple con el nivel de protección del CEDH.

En concreto, la demanda ante el TEDH la presentaron el señor Sedjic, de origen romaní, y el señor Finci, de origen judío, contra el Estado de Bosnia-Herzegovina. La demanda se fundamentaba en el hecho de que estas personas, atendida la etnia a la que pertenecían, no podían concurrir a las elecciones de la Cámara de los Pueblos y a las elecciones presidenciales en el país indicado.

La prohibición de intervención tiene su fundamento en la misma Constitución política de Bosnia-Herzegovina. Dicha Constitución establece una clara distinción entre los «pueblos constituyentes» y los «otros» pueblos. En concreto, entre los primeros, se incluye a las personas que pertenecen al grupo de los bosniacos, al de los croatas o al de los serbios. Los «otros» son los miembros de cualesquiera otras minorías étnicas y personas que declaran que no pertenecen a ningún grupo en particular, por ejemplo, porque han contraído matrimonio con una persona de otro origen étnico, o porque los padres son de origen étnico distinto, o por otras razones. Los demandantes pertenecían a dicha categoría de "otros» grupos étnicos.

Para comprender adecuadamente esta distinción y clasificación en grupos étnicos, debe tenerse presente que, en la antigua Yugoslavia, la pertenencia a un grupo étnico era decidida por las mismas personas, en virtud de un «sistema de autoclasificación ${ }^{22} »$. Como indica el TEDH en los antecedentes del caso, «no se requería el cumplimiento de ningún criterio objetivo, como el conocimiento de una lengua determinada o la pertenencia a una reli-

enmienda a la ordenanza y la supresión, en la Constitución maltesa, de toda referencia a las diligencias por atentado a los privilegios. El Gobierno se opone a ello.

El Tribunal señala que el Convenio no le habilita a admitir esta solicitud. Recuerda que es al Estado a quien corresponde escoger los medios a utilizar en su orden jurídico interno para reparar una situación que ha llevado consigo una violación (ver, mutatis mutandis, la Sentencia Zanghi de 19 febrero 1991 [TEDH 1991, 21], serie A núm. 194-C, pg. 48, ap. 26)».

21 BDAW TEDH JUR\2009\493814.

22 Véase la STEDH, circunstancias del caso, párr. 11. 
gión concreta. Tampoco se requería la aceptación por los demás miembros del grupo étnico en cuestión». Este sistema de autoclasificación es el que hereda Bosnia y Herzegovina. De esta manera, los demandantes que afirmaban ser de etnia romaní y de etnia judía quedaban excluidos de los grupos constituyentes.

En los párrs. 42, 43 y 44, el TEDH lleva a cabo una serie de consideraciones de carácter general sobre la diferencia de trato basada en razones étnicas ${ }^{23}$.

23 Así afirma: «El Tribunal recuerda que la discriminación consiste en tratar de forma distinta, sin justificación objetiva y razonable, a personas que se encuentran en situaciones análogas. Un trato diferenciado carece de "justificación objetiva y razonable" cuando no persigue un "fin legítimo" o no existe una "relación razonable de proporcionalidad entre los medios empleados y el fin perseguido" (véase, entre muchos otros precedentes, la Sentencia Andrejeva contra Letonia [GS], núm. 55707/2000, ap. 81, 18 de febrero de 2009). El alcance del margen de apreciación de que disponen las Partes Contratantes a este respecto varía según las circunstancias, los ámbitos y el contexto (ibídem, ap. 82).

43. El origen étnico y la raza son conceptos análogos. Mientras que el concepto de raza tiene su origen en la idea de una clasificación biológica de los seres humanos en subespecies basándose en características morfológicas tales como el color de la piel o los rasgos faciales, el origen étnico procede de la idea de que los grupos sociales se distinguen especialmente por una comunidad de nacionalidad, de fe religiosa, lengua, origen cultural y tradicional y entorno. La discriminación basada en el origen étnico de una persona constituye una forma de discriminación racial (véase la definición, citada en el apartado 19 supra, adoptada por la Convención Internacional sobre la Eliminación de todas las Formas de Discriminación Racial, y la mencionada en el apartado 23 supra, adoptada por la Comisión Europea contra el Racismo y la Intolerancia). La discriminación racial constituye una forma de discriminación especialmente aborrecible que, habida cuenta de la peligrosidad de sus consecuencias, requiere una vigilancia especial y una reacción enérgica por parte de las autoridades. Éstas deben recurrir a todos los medios a su alcance para combatir el racismo, reforzando así la concepción democrática de la sociedad, en la que la diversidad se perciba no como una amenaza, sino como una riqueza (véanse Sentencias Natchova y otros contra Bulgaria [GS], núms. 43577/1998 y 43579/1998, ap. 145, TEDH 2005-VII, y Timichev, anteriormente citada, ap. 56).

44. En este contexto, cuando una diferencia de trato se basa en la raza, el color o el origen étnico, la noción de justificación objetiva y razonable debe interpretarse de la forma más estricta posible (Sentencia D.D. y otros, anteriormente citada, ap. 196). Por otra parte, el Tribunal ha considerado que en una sociedad democrática contemporánea basada en los principios de pluralismo y de respeto por las distintas culturas, no hay posibilidad de justificación objetiva en ninguna diferencia de trato basada exclusivamente o de manera determinante en el origen étnico de una persona 
Estas consideraciones generales son las que le llevan a analizar el caso concreto para reconocer que esa diferencia entre los pueblos a la que se refiere la Constitución buscaba el restablecimiento de la paz en el momento en que se aprueba la texto constitucional como anexo al Acuerdo Marco General para la Paz en Bosnia-Herzegovina (Acuerdo de Paz de Dayton), aprobado en Dayton el 21 de noviembre de $1995^{24}$. Así se subraya en el párr. 45, en el que se afirma:

Volviendo al presente caso, el Tribunal señala que para poder concurrir a las elecciones a la Cámara de los Pueblos de Bosnia y Herzegovina es necesario declarar la pertenencia a uno de los «pueblos constituyentes». Los demandantes que manifiestan ser de origen romaní y judío, respectivamente, y que no declaran pertenecer a ningún "pueblo constituyente», carecen pues de esta posibilidad (apartado 11 supra). El Tribunal señala que esta regla de exclusión perseguía al menos un fin globalmente compatible con los objetivos generales del Convenio reflejados en su Preámbulo, el restablecimiento de la paz. Cuando se adoptaron las disposiciones constitucionales enjuiciadas, imperaba en el país un frágil alto el fuego. Las disposiciones en cuestión pretendían poner fin a un conflicto brutal marcado por actos de genocidio y de «depuración étnica». La naturaleza del conflicto era tal que era necesaria la aprobación de los «pueblos constituyentes» (bosníacos, croatas y serbios) para garantizar la paz. Ello explica, sin necesariamente justificarla, la ausencia de representantes de las otras comunidades (especialmente las comunidades romaní y judía locales) en las negociaciones de paz y el deseo de los negociadores de velar por la igualdad efectiva entre los «pueblos constituyentes» en la sociedad post-conflicto.

(ibídem, ap. 176). Así las cosas, el artículo 14 del Convenio no prohíbe a las Partes Contratantes tratar a grupos de forma diferenciada con el propósito de corregir "desigualdades fácticas" entre ellos; de hecho, en ciertas circunstancias, es la ausencia de un trato diferenciado para corregir una desigualdad el que, sin una justificación objetiva y razonable, puede constituir una violación de la disposición en cuestión (véase el asunto "relativo a ciertos aspectos del régimen lingüístico de la enseñanza en Bélgica” previamente citado, ap. 10 y Sentencia Thlimmenos contra Grecia [GS], núm. 34369/1997, ap. 44, TEDH 2000-IV; y D.H. y otros, anteriormente citada, ap. 175)».

24 Debe tenerse presente, como subraya el TEDH en el párr. 6 de los hechos de la sentencia, que «la Constitución fue redactada y aprobada sin que se aplicaran los procedimientos que habrían podido conferirle la legitimidad democrática. Negociada y publicada en una lengua extranjera, el inglés, representa el único caso de Constitución que nunca ha sido publicada formalmente en las lenguas oficiales del país en cuestión». 
Sin embargo, en la adhesión de Bosnia y Herzegovina al CEDH, el TEDH considera que la diferencia de trato y la exclusión del sufragio pasivo a los «otros» ciudadanos suponen una clara violación del derecho reconocido en el art. 14 del CEDH. En la línea con lo que hemos indicado, el TEDH no condenó al Estado a modificar su texto constitucional, sino, simplemente, a indemnizar a los demandados (Kucukalic, 2009: 135-152). En concreto, 1000 euros de indemnización en favor del primero de los demandantes y 20000 euros en favor del segundo. Es obvio que una reforma constitucional hubiera implicado que en el futuro no volvieran a producirse nuevas violaciones. Sin embargo, como la reforma no tuvo lugar, se han presentado nuevas demandas ante el TEDH fundadas en el mismo tipo de violación.

Sobre esta misma violación se pronuncia también en la STEDH de 15 de julio de 2014 ${ }^{25}$, caso Zornic contra Bosnia-Herzegovina. La demanda ante el TEDH que dio origen a esta sentencia fue presentada por una ciudadana bosnia-herzegovina que no se adscribió a ninguno de los pueblos constituyentes de dicho país. Por lo tanto, fue excluida de la participación en el proceso electoral a la presidencia y a la casa del pueblo. En esta sentencia, el TEDH reconoce que el pronunciamiento que en su día dictó en la sentencia del caso Sejdic y Finci implicaba que el Estado condenado adoptara medidas que acabaran protegiendo a todas las personas que se encontraban en la misma situación que los demandantes. En el párr. 39 de la sentencia se indica:

El Tribunal recuerda que el artículo 46 del Convenio (RCL 1999, 1190, 1572), interpretado a la luz del artículo 1, impone al Estado demandado la obligación legal de aplicar, bajo la supervisión del Comité de Ministros, medidas adecuadas generales y/o individuales para garantizar el derecho del demandante que el Tribunal ha considerado violado. Dichas medidas deben ser tomadas también respecto del resto de personas en la situación del demandante, en especial solventando los problemas que han llevado a las conclusiones del Tribunal (véase Scozzari y Giunta contra Italia [GS] [TEDH 2000, 391], núms. 39221/98 y 41963/98, ap. 249, TEDH 2000 VIII; Karanović contra Bosnia-Herzegovina, núm. 39462/03, ap. 28, 20 de noviembre de 2007 [JUR 2007, 334165]; Čolić y otros contra Bosnia-Herzegovina, núms. 1218/07 y otros, ap. 17, 10 de noviembre de 2009 [JUR 2009, 448860]; Burdov contra Rusia (núm. 2) [JUR 2009, 123], núm. 33509/04, ap. 125, TEDH 2009 [...]; y Greens y M.T. contra el Reino Unido [JUR 2010, 382394], núms. 60041/08 y 60054/08, ap. 106, TEDH 2010 (extractos).

En el párr. 41 hace referencia a las medidas de ejecución forzosa que deberían haberse adoptado en relación con la anterior sentencia que hubieran

25 BDAW TEDH\201449. 
evitado que se repitiera una demanda ante el TEDH. En concreto, reconoce que, de acuerdo con lo fijado por el Comité de Ministros del Consejo de Europa, debería haberse procedido a realizar una reforma constitucional en dicho país ${ }^{26}$.

Y con ello, en el párr. 43 llega a la conclusión de la necesidad de que Bosnia y Herzegovina acomode su Constitución política al CEDH. En concreto, afirma:

En Sejdić y Finci el Tribunal observó que cuando se establecieron las disposiciones constitucionales impugnadas estaba en vigor un muy frágil alto el fuego y que las disposiciones fueron diseñadas para poner fin a un brutal conflicto marcado por el genocidio y la «limpieza étnica» (véase ibíd., ap. 45). La naturaleza del conflicto era tal que la aprobación de los "pueblos constituyentes» se hacía necesaria para garantizar la paz (ibíd.). No obstante, ahora, más de dieciocho años después del final del trágico conflicto, ya no existiría ninguna razón para el mantenimiento de las controvertidas disposiciones constitucionales. El Tribunal espera que los acuerdos democráticos se realicen sin demora. Habida cuenta de la necesidad de garantizar la efectiva democracia política, el Tribunal considera que ha llegado el momento de un sistema político que proporcione a todos los ciudadanos de Bosnia-Herzegovina el derecho a presentarse a las elecciones a la Presidencia y a la Casa del Pueblo de Bosnia-Herzegovina sin discriminación basada en la pertenencia étnica y sin otorgar

26 Se afirma: «Conforme al artículo 46.2, Sejdić y Finci está actualmente bajo la supervisión del Comité de Ministros, quien ha examinado regularmente los desarrollos internos y busca un rápido final a la situación de incumplimiento. Siempre ha considerado que deberían adoptarse una serie de enmiendas a la Constitución de Bosnia-Herzegovina y a la legislación electoral para la ejecución de la presente sentencia. El Comité de Ministros aprobó tres resoluciones provisionales instando a las autoridades de Bosnia-Herzegovina a tomar todas las medidas necesarias para la plena ejecución de esa sentencia mediante la adopción de medidas encaminadas a eliminar la discriminación contra quienes no están afiliados con un pueblo constituyente para poder presentarse a las elecciones a la Casa del Pueblo y a la Presidencia de Bosnia-Herzegovina y establecer la conformidad de su Constitución y de su legislación electoral conforme a los requisitos del Convenio sin más dilación (véase el apartado 12; Ver también las resoluciones núms. 1701(2010), 1725(2010) y 1855(2012) y Recomendación núm. 2025(2013) de la Asamblea Parlamentaria del Consejo de Europa). En su tercera resolución en particular el Comité de Ministros hace un llamamiento al Estado demandado "a garantizar inmediatamente que el marco legislativo y constitucional sea conforme con los requisitos del Convenio y que por tanto las elecciones de octubre de 2014 se celebren sin ninguna discriminación contra aquellos ciudadanos que no estén afiliados con ninguno de los "pueblos constituyentes" (véase apartado 12)». 
derechos especiales a los pueblos constituyentes excluyendo a las minorías o a los ciudadanos de Bosnia-Herzegovina.

Nótese que el TEDH no se pronuncia expresamente sobre la obligación del Estado demandado de modificar su Constitución. Sin embargo, puede apreciarse un ligero cambio en su jurisprudencia, pues expresamente indica que es hora de que Bosnia y Herzegovina modifique su texto constitucional, habida cuenta de que las circunstancias políticas han cambiado desde el fin de la guerra. Desde nuestro punto de vista, supone un paso adelante en relación con la posibilidad de que una persona directamente afectada por una disposición constitucional pueda conseguir un pronunciamiento del TEDH que acabe beneficiando a otras personas que potencialmente podrían sufrir una lesión en su derecho.

Más recientemente, podemos hacer referencia al caso Slaku contra Bosnia y Herzegovina, sentencia de 26 de mayo de $2016^{27}$. El supuesto de hecho que da origen a la demanda de amparo es muy parecido al primero de los casos a los que nos hemos referido. En este supuesto, no obstante, el demandante de amparo era un integrante de la minoría étnica albanesa. Por ese motivo, al no pertenecer a las etnias constituyentes, se le impidió participar en el proceso electoral $^{28}$. El TEDH declara que dicha exclusión prevista en la Constitución política de la nación no es compatible con el $\mathrm{CEDH}^{29}$.

Son ya varios años los que han pasado desde la primera sentencia de condena contra Bosnia y Herzegovina, y el mismo TEDH reconoce en la sentencia que estudiamos que el hecho de que el Estado condenado no haya adaptado su regulación interna al sistema europeo de protección de derechos humanos agrava su responsabilidad, así como supone una clara amenaza para la eficacia del sistema ${ }^{30}$.

Es cierto que el Comité de Ministros del Consejo de Europa ha dirigido a Bosnia y Herzegovina diferentes resoluciones para que modifique su ordenamiento interno y lo acomode al sistema, pero el TEDH constata en el párr. 38 de la sentencia que ese país no ha atendido a dichos requerimientos. En esta sentencia, de igual modo que en la anterior, se vuelve a indicar que, después de haber transcurrido varios años desde el fin del conflicto bélico, ya ha llegado el momento de que se garantice a todos los ciudadanos de ese país el derecho

\footnotetext{
BDAW JUR\2016\121383.

Véase párr. 29.

29 Véase párr. 33.

30 Véase párr. 37.
} 
a concurrir en condición de igualdad a las elecciones ${ }^{31}$. Obviamente, atender a este requerimiento obligaría a modificar el texto constitucional.

En el caso Pilav contra Bosnia y Herzegovina, STEDH de 9 de junio de $2016^{32}$, el TEDH vuelve a enfrentarse al problema de la discriminación. Aunque en este caso hay un matiz interesante. En concreto, debe tenerse presente que el Estado de Bosnia y Herzegovina es una república federal que está integrada por dos entidades autónomas: la federación de Bosnia y Herzegovina ${ }^{33}$ y la República Srpska ${ }^{34}$. Según los acuerdos de paz a los que nos hemos referido más arriba, la presidencia de la República está integrada por tres personas: un bosniaco y un croata, ambos elegidos por la federación de Bosnia y Herzegovina, y un serbio, elegido por la República de Srpska ${ }^{35}$.

Este caso resulta muy interesante, pues en los tres anteriores nos encontramos a personas que no pertenecían a una etnia constituyente o que no declararon a qué etnia pertenecían. Sin embargo, en este caso, el demandante de amparo pertenece a una de las etnias constituyentes, pues es bosniaco. Sin embargo, reside en una república en la que esa condición le impide presentarse a presidente de la República ${ }^{36}$.

El TEDH considera que la prohibición de presentarse a la presidencia de la República también es una discriminación, ya que, con independencia de la entidad en la que se resida, se está decidiendo sobre la presidencia de la República $^{37}$. Es por ello por lo que el TEDH llega a la conclusión de que la exclusión del demandante de amparo del proceso electoral supone una discriminación por motivos étnicos, combinada con el dato del lugar de residencia ${ }^{38}$.

Sin embargo, en la sentencia no se pronuncia el TEDH expresamente sobre el conflicto de la Constitución con el CEDH, y, por lo tanto, sobre la modificación del texto constitucional.

\section{b2) Sentencia piloto}

El Comité de Ministros, en su sesión de 12 de mayo de 2004, adoptó una resolución en virtud de la cual invitaba al TEDH, cuando conociera de las demandas individuales, a identificar, cuando fuera posible, el problema estructural subyacente. Esta invitación se efectuó, sobre todo, cuando se trató

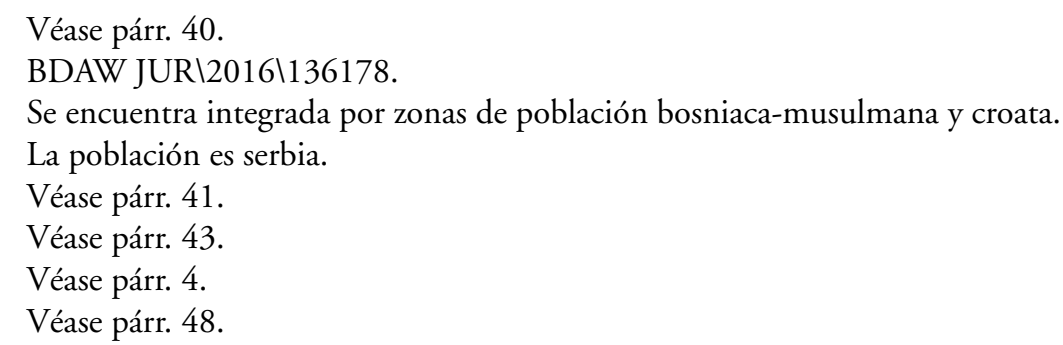


de problemas que pudieran dar origen a numerosas demandas, ayudando a los Estados parte a buscar una solución adecuada a dicho problema. De igual modo, se pretendía facilitar la labor de control del cumplimiento por parte del Comité de Ministros (Casadevall, 2012: 115). Un mes después, se dictó la primera sentencia piloto. El art. $61 \mathrm{RTEDH}$ regula el procedimiento de la sentencia piloto, así como sus presupuestos.

En concreto, en primer lugar, debe detectarse un problema estructural o sistémico u otra disfunción similar en el Estado demandado (art. 61.1 RTEDH) (Abrisketa, 2013: 81-83). Dicho problema puede afectar a su ordenamiento jurídico o práctica judicial o administrativa, por ejemplo. El TEDH ha entendido que las sentencias piloto se pueden dictar cuando se trata de supuestos de violaciones repetitivas y a gran escala, ocasionadas por "carencias o disfunciones estructurales y sistemáticas en el orden jurisdiccional de ciertos Estados» (Casadevall, 2012: 116)

En tercer lugar, es preciso que la fundamentación fáctica de las demandas presentadas (o que se puedan presentar) permita identificar la misma deficiencia estructural. Como puede apreciarse, estamos hablando de la existencia de varios procesos pendientes (o que puedan originarse) sobre la base de la misma causa de pedir. Es decir, no estamos refiriéndonos a procesos idénticos, pues la litispendencia impediría su desarrollo. Nos referimos a que haya (o pueda haber) diferentes procesos fundados en el mismo supuesto fáctico: la deficiencia estructural o sistémica que afecte al ordenamiento jurídico o al sistema judicial de un determinado país.

En cuarto lugar, se requiere que exista identidad subjetiva en el lado pasivo de los procesos iniciados (o que puedan iniciarse). Al respecto, presupuesto que necesariamente debe concurrir y que está implícito en la concreción de los anteriores es el que el Estado demandado (efectiva o potencialmente) sea el mismo. La razón es evidente. La deficiencia estructural o sistémica es la que provoca (o puede provocar) que ese Estado viole repetidamente el mismo derecho correspondiente a diversas personas.

Desde un punto de vista procedimental, el art. 61.2b RTEDH es claro al indicar que el TEDH puede decidir aplicar el procedimiento que permita la emisión de una sentencia piloto, bien de oficio o a instancia de parte (Morte, 2013: 921). En este último caso, se contemplan dos posibilidades. La primera, que todas las partes procesales soliciten conjuntamente que se acuerde iniciar un procedimiento que permita la emisión de una sentencia piloto. La segunda situación es que la solicitud venga formulada por una sola de las partes. En este sentido, la solicitud puede ser formulada indistintamente por el demandante o también por el Estado demandado. No es condición sine qua non que todas las partes formulen conjuntamente la solicitud de iniciar este tipo de procedimiento. 
El art. 61.2a RTEDH establece que antes de decidir seguir el procedimiento de sentencia piloto el TEDH debe prestar audiencia a las partes. En relación con esta exigencia, queremos realizar básicamente dos observaciones.

La primera, que este trámite de audiencia debe considerarse necesario en el caso en que el recurso al procedimiento de sentencia piloto se pretenda iniciar de oficio o a instancia de alguna de las partes. Por el contrario, si todas las partes han presentado de manera conjunta su solicitud de recurrir a este procedimiento, no tiene sentido iniciar el trámite de audiencia.

El objeto de este trámite de audiencia es solamente discutir y conocer los argumentos del Tribunal o de la parte contraria acerca de la concurrencia del presupuesto de la existencia de deficiencia estructural o sistémica en el Estado demandado, así como que la demanda se presta a este procedimiento de sentencia piloto.

El art. 61.10 RTEDH exige que el inicio del procedimiento que permita lograr una sentencia piloto deba publicarse en la página web del TEDH. Y a su vez se dispone que la demanda del procedimiento piloto tendrá un tratamiento prioritario (art. 61.2c RTEDH) (ibid.: 921).

$\mathrm{Si}$ atendemos a los apdos. 3 y 4 del RTEDH, podemos distinguir dos tipos de contenidos en la sentencia: preceptivos y facultativos.

Con carácter preceptivo, la sentencia piloto debe incluir:

1) La identificación de la naturaleza del problema estructural o sistémico, o de la disfunción, constatado en el ordenamiento jurídico del Estado demandado.

2) Indicación de las medidas reparatorias que el Estado condenado debe adoptar a nivel interno en aplicación del fallo de la sentencia.

En este sentido, hay que señalar que la sentencia piloto da respuesta a la demanda individual presentada, por lo tanto, debe pronunciarse sobre las medidas particulares que deben adoptarse en favor del demandante. Pero, a su vez, fija las medidas de carácter general que habrían evitado que la violación se hubiera producido y que, por lo tanto, pueden evitar que en el futuro puedan producirse nuevas violaciones (ibid.: 83-85). En definitiva, el TEDH asume un rol más activo, pudiendo fiscalizar el ordenamiento interno de un Estado (ibid:: 75).

Por otro lado, hay que añadir que, en el supuesto en que el demandante hubiera solicitado una satisfacción equitativa al amparo del art. $41 \mathrm{CEDH}$, el TEDH puede reservarse el análisis de esa cuestión, a la espera del cumplimiento por parte del Estado demandado de las medidas individuales y generales impuestas en la sentencia (art. 61.5 RTEDH). 
Con este carácter facultativo, el TEDH puede fijar un plazo para la adopción de las medidas mencionadas anteriormente. La fijación del plazo en concreto depende de la naturaleza de las medidas impuestas y de la rapidez con la cual se puede poner remedio al problema estructural a nivel interno (art. 61.4 RTEDH).

Desde un punto de vista formal, el art. 61 RTEDH no contiene especialidad alguna. Por lo tanto, formalmente, las sentencias piloto son idénticas al resto de sentencias que pueda dictar el TEDH.

De entrada, son aplicables a este tipo de sentencias los requisitos de publicidad que se establecen con carácter general para todas las sentencias dictadas por el TEDH. De este modo, la sentencia piloto puede ser leída en audiencia pública por el presidente de la sala o por el magistrado en que aquel haya delegado. Para ello, los representantes de las partes deben ser debidamente informados de la fecha de la audiencia. En el caso en que no se lea en audiencia pública, la sentencia debe notificarse a las partes por escrito (art. 77.2 RTEDH).

Como requisitos específicos de publicidad, debe tenerse presente el art. 61.9 y 10 RTEDH. Por un lado, el TEDH debe comunicar al Comité de Ministros, a la Asamblea Parlamentaria, al secretario general del CE y al comisario por los Derechos del Hombre del Consejo de Europa la emisión de cualquier sentencia piloto o de otra sentencia que, sin ser piloto, haya identificado un problema estructural sistémico en un Estado parte del CE (art. 61.9 RTEDH).

Por otro lado, la emisión de una sentencia piloto, su ejecución y el cierre del procedimiento deben publicarse en la página web del TEDH (art. 61.10 RTEDH).

La regulación contenida en el art. 61 RTEDH nos permite clasificar los efectos de la sentencia piloto desde dos puntos de vista diferentes.

$\mathrm{Si}$ atendemos a los sujetos que pueden haber sido afectados por la deficiencia estructural del Estado condenado, la emisión de la sentencia piloto no impide que puedan volverse a presentar nuevas demandas contra dicho Estado basadas en esa deficiencia estructural. Mientras siga subsistiendo el fallo estructural o sistémico, se seguirán produciendo nuevas violaciones de derechos.

Ahora bien, si el Estado condenado atiende a las medidas generales impuestas, indirectamente, la sentencia acaba beneficiando a sujetos afectados que no han sido parte en el proceso. Es en este punto en el que se constata, claramente, que la sentencia piloto es un mecanismo que sirve para la protección colectiva de derechos.

Ahora bien, el efecto que provoca la emisión de una sentencia piloto, desde el punto de vista procedimental, es relevante. Al respecto, el TEDH puede decidir la suspensión de todos los procesos que ya estén pendientes 
contra el mismo Estado y fundamentados en la misma deficiencia estructural (art. 61.6. ${ }^{\mathrm{a}}$ RTEDH) (Morte, 2013: 85-86).

Desde nuestro punto de vista, esta disposición también debe aplicarse por analogía a los casos en que tras la emisión de la sentencia se presenten nuevas demandas frente al Estado basadas en la misma deficiencia estructural. Entendemos que dichas demandas deben ser admitidas a trámite y provocar, por lo tanto, el efecto de litispendencia. Pero una vez iniciado el proceso, debe acordarse la suspensión del mismo.

En todo caso, la suspensión de estos procedimientos se lleva a cabo a la espera de que el Estado condenado adopte las medidas que se han indicado en la parte dispositiva de la sentencia.

La suspensión debe ser comunicada a las partes de todos los procesos afectados, así como cualquier otra nueva circunstancia relevante que afecte a su causa (art. 61.6b RTEDH). No obstante, en cualquier momento, el TEDH puede levantar la suspensión de un determinado procedimiento si fuera necesario por razones de interés de la justicia (art. 61.6c RTEDH).

Los procesos suspendidos pueden acabar de dos maneras, ya sea de manera anormal o normal. Vamos a referirnos separadamente a cada uno de estos supuestos.

Los procesos terminan de manera anormal cuando el Estado condenado adopta las medidas necesarias para dar cumplimiento al fallo o parte dispositiva de la sentencia piloto. En ese caso, además, ofrece a los demandantes, en cada uno de esos procesos, un arreglo amistoso, que deberá ser fiscalizado por el TEDH. Dichos procesos, por esta vía, terminan de manera anticipada sin que el TEDH tenga que entrar a pronunciarse sobre el fondo del asunto (Pastor, 2000: 167; Pastor, 2009: 12-13; Cacho, 2007: 1-30). Sin embargo, como hemos señalado, terminan con la satisfacción del interés particular del demandante. Por lo tanto, el mecanismo de la sentencia piloto, además de permitir extender los efectos de la sentencia a la protección de terceros, permite luchar contra la saturación del Tribunal, a la vez que evita «repetir una y otra vez el mismo mensaje y de atribuir una satisfacción equitativa caso por caso" (Casadevall, 2012: 116).

Sin embargo, es posible que, en relación con un proceso suspendido, o con todos los que han sido objeto de suspensión, se reanude la tramitación procedimental. En estos casos, el proceso terminaría de manera normal, entrando el TEDH a conocer del fondo del asunto. Al respecto, debe tenerse presente que el TEDH puede decidir la reanudación de la tramitación de un procedimiento suspendido tras la emisión de la sentencia piloto, si hubiera un interés de buena administración de la justicia (art. 61.6c RTEDH). Y, por otro lado, se procede a levantar la suspensión de todos los procedimientos 
afectados por la emisión de la sentencia piloto cuando el Estado no atiende a las medidas impuestas en el fallo de la sentencia (art. 61.8 RTEDH).

\section{CONCLUSIONES}

1. ${ }^{\text {a }}$ El Estado social y democrático de derecho que nace tras el fin de la Segunda Guerra Mundial se pretende construir sobre la base del respeto a la dignidad de la persona y el reconocimiento de los derechos que son los inherentes. En ese contexto, el CE ha desempeñado un papel esencial. Al menos cuantitativamente, en cuanto al número de Estados que forman parte del sistema, puede decirse que se ha logrado el objetivo. No obstante, es discutible en relación con el nivel de protección o reconocimiento de los derechos.

2. ${ }^{\mathrm{a}} \mathrm{La}$ creación del TEDH ha contribuido a lograr el anterior objetivo, en la medida en que ha supuesto la creación de un órgano jurisdiccional supranacional ante el que se pueden presentar las demandas individuales por violación de derechos humanos. Creemos que es importante destacar que se trata del primer órgano internacional creado para la protección de derechos humanos y que pone en evidencia la crisis del modelo clásico liberal de la justicia limitada al ámbito territorial de las fronteras de los Estados.

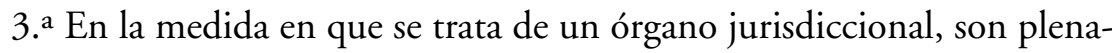
mente aplicables los principios y teorías básicas sobre la estructura procesal. En este sentido, es criticable, por ejemplo, que la Gran Sala, al resolver la impugnación contras las sentencias dictadas por las salas, esté integrada por magistrados que integraron la sala que dictó la sentencia que se impugna. El derecho a un proceso con todas las garantías también debe regir en el proceso seguido ante el TEDH.

4. ${ }^{\mathrm{a}}$ Las sentencias que puede dictar el TEDH pueden ser de diferentes tipos. No obstante, creemos que las más relevantes son las que se denominan sentencias condenatorias. Con carácter general, ha sido frecuente que las sentencias se limitaran a establecer medidas de reparación individual. Sin embargo, nosotros creemos que la tutela judicial efectiva no se logra solamente imponiendo al demandado una obligación de pagar o reparar en sentido individual. En ocasiones, nos encontramos con que la tutela solamente se obtiene de manera completa si se incluyen medidas de carácter general que debe adoptar el Estado.

5. ${ }^{a} \mathrm{El} \mathrm{TEDH}$ ha sido reacio a establecer esas medidas de carácter general. Un ejemplo de ello se encuentra en los casos en que se detecta que la violación denunciada está producida por una norma de carácter constitucional. Es decir, que es una disposición de la Constitución política de una nación la que viola derechos humanos. En este punto, el sistema europeo adopta una posición 
más cautelosa que la que podemos apreciar en el sistema interamericano de protección de derechos humanos.

6. a Precisamente en un intento de facilitar que los Estados puedan cumplir de mejor manera las sentencias del TEDH, en los últimos tiempos se han ido extendiendo las sentencias en las que al Estado demandado se le indica una serie de medidas generales que debe adoptar. Ese camino se está transitando con las denominadas sentencias piloto.

7. ${ }^{\text {a }}$ Es cierto que con este tipo de sentencias se ha dado un paso adelante en la búsqueda de formas de tutela colectiva. Sin embargo, creemos que aún hay asuntos pendientes, sobre todo, en los casos en los que el Estado no elimine el fallo estructural o sistémico, y, por lo tanto, se sigan produciendo esas violaciones masivas. $\mathrm{Y}$, por otro lado, creemos que la falta de una postura del TEDH sobre el denominado control de convencionalidad impide que lo resuelto en una sentencia piloto pueda hacerse extensivo a otros Estados que no hayan sido parte en el procedimiento en que se dicta la sentencia.

\section{Bibliografía}

Abrisketa Uriarte, J. (2013). Las sentencias piloto: El Tribunal Europeo de derechos humanos, de juez a legislador. Revista Española de Derecho Internacional, 65 (1), 73-99.

Bondia García, D. (2008). El sistema europeo de protección de los derechos humanos. En J. Bonet i Pérez y V. M. Sánchez (coords.). Los derechos humanos en el siglo XXI: continuidad y cambios (pp. 219-252). Barcelona: Huygens.

Cacho Sánchez, Y. (2007). Cómo mejorar la eficacia del Tribunal Europeo de Derechos Humanos: las medidas propuestas por el grupo de sabios en su informe de 15 de noviembre de 2006. Revista General de Derecho Europeo, 12 (6), 1-30.

Cancio Fernández, R. C. (2017). La protección de los derechos humanos en el sistema europeo. En J. M. Enríquez Sánchez, A. Masferrer y R. E. Aguilera Portales (coords.). Derechos humanos. Un análisis multidisciplinar de su teoría y praxis (pp. 291-328). Madrid: Universidad Nacional de Educación a Distancia.

Canosa Usera, R. (2009). La interpretación evolutiva del Convenio Europeo de Derechos Humanos. En F. J. García Roca y P. Fernández Sánchez (coords.). Integración europea a través de derechos fundamentales: de un sistema binario a otro integrado (pp. 79-93). Madrid: Centro de Estudios Políticos y Constitucionales.

Carrillo Salcedo, J. A. (1998). Vínculos entre la Declaración Universal de Derechos Humanos y el sistema europeo de protección de los derechos humanos. En Asociación para las Naciones Unidas en España, X. Pons Rafols (coord.). La Declaración Universal de Derechos Humanos: comentario artículo por artículo (pp. 63-72). Barcelona: Icaria. 
Casadevall, J. (2001). El Tribunal Europeo de los Derechos Humanos (análisis teórico-práctico de su funcionamiento). En A. Blanc Altemir (coord.). La protección internacional de los derechos humanos a los cincuenta años de la Declaración Universal (pp. 129-146). Madrid: Tecnos.

(2012). El Convenio Europeo de Derechos Humanos, el Tribunal de Estrasburgo y su jurisprudencia. Valencia: Tirant lo Blanch.

Cucarella Galiana, L. A. (2016). Medios de impugnación en el sistema europeo de protección de los derechos humanos. En M. Ortells Ramos y R. Bellido Penadés (coords.). Los recursos en el proceso civil: continuidad y reforma (pp. 307-325). Madrid: Dykinson.

Fernández Sánchez, P. (2000). Las obligaciones procedimentales ante el nuevo Tribunal Europeo de Derechos Humanos. En Hacia una Justicia Universal: XXI Jornadas de Estudio, 9 a 11 de junio de 1999 (pp. 165-168). Madrid: Dirección General del Servicio Jurídico del Estado.

Fernández Sola, N. (2000). Dos modelos de Justicia internacional: el Tribunal Europeo de Derechos Humanos y la Corte Penal Internacional. En Hacia una Justicia Universal: XXI Jornadas de Estudio, 9 a 11 de junio de 1999 (pp. 181-192). Madrid: Dirección General del Servicio Jurídico del Estado.

García Jiménez, M. E. (1998). El convenio europeo de derechos humanos en el umbral del siglo XXI. Valencia: Tirant lo Blanch.

Gimeno Sendra, V. (1998). La experiencia de los «juicios de Nürenberg» y la necesidad de crear el Tribunal Penal Internacional. La Ley: Revista Jurídica Española de Doctrina, Jurisprudencia y Bibliografia, 1, 1766-1768.

Gimeno Sendra, V., Moral, A. del, Morenilla Allard, P. y Díaz Martínez, M. (2007). Los derechos fundamentales y su protección jurisdiccional. Madrid: Colex.

González Montes, J. L. (2000). Los avances en la defensa de los derechos humanos en el cincuenta aniversario de la Declaración Universal de Derechos Humanos. En Hacia una Justicia Universal: XXI Jornadas de Estudio, 9 a 11 de junio de 1999 (pp. 13-36). Madrid: Dirección General del Servicio Jurídico del Estado.

Kucukalic Ibrahimovic, E. (2009). El lugar de «los otros» en la Constitución de Bosnia y Herzegovina. La representación constitucional de las minorías y sus consecuencias sobre los derechos individuales. Cuadernos Constitucionales de la Cátedra Fadrique Furió Ceriol, 67-68, 135-152.

Morte Gómez, C. (2010). Eficacia de las sentencias del Tribunal Europeo de Derechos Humanos. En Curso de Derechos Humanos de Donostia-San Sebastián: volumen XI: La eficacia del Derecho Internacional de los derechos humanos (pp. 225-242). Bilbao: Universidad del País Vasco.

_ (2013). El procedimiento ante el Tribunal Europeo de Derechos Humanos. En M. Nogueira Guastavino y G. García Becedas (coords.). Lecciones de Jurisdicción social (pp. 920-921). Valencia: Tirant lo Blanch.

Pastor Palomar, A. (2000). El sistema europeo: el Consejo de Europa (I). En C. Fernández de Casadevante Romaní (dir.). Derecho internacional de los derechos humanos. Madrid: Dilex. 
Pastor Riduejo, J. A. (2009). La Carta de Derechos fundamentales de la Unión Europea y la adhesión al Convenio Europeo según el Tratado de Lisboa. En J. García Roca y P. A. Fernández Sánchez (coords.). Integración europea a través de derechos fundamentales: de un sistema binario a otro integrado (pp. 12-13). Madrid: Centro de Estudios Políticos y Constitucionales.

Ripoll Carulla, S. (2008). El sistema europeo de protección de los Derechos Humanos y el Derecho español. En J. M. Beneyto Pérez, P. Argerey Vilar y A. Rincón García Loygorri (coords.). Cincuenta años de construcción europea: grandes logros del pasado y desafios para el futuro (pp. 99-116). Madrid: Biblioteca Nueva: Instituto Universitario de Estudios Europeos de la Universidad CEU San Pablo.

Ruiloba Alvariño, J. (2006). El Tribunal Europeo de Derechos Humanos: organización y funcionamiento. Anuario de la Escuela de Práctica Jurídica, 1.

Sánchez Legido, A. (1995). La reforma del mecanismo de protección del convenio europeo de derechos humanos. Madrid: Colex. 